\title{
Beginning of outcome-based medical education: development of medical schools' mission statements based on stakeholders' priority
}

\author{
Youngjon $\mathrm{Kim}^{1}$ and Hyoseon $\mathrm{Choi}^{2}$ \\ ${ }^{1}$ Department of Medical Education, Wonkwang University School of Medicine, Iksan, and ${ }^{2}$ Deparment of Medical \\ Education, Chosun University College of Medicine, Gwangju, Korea
}

Background: Many studies report the positive effects of outcome-based education in improving medical education quality. An important aspect of outcome-based education is the statement of learning outcomes, which is closely associated with medical schools' mission, vision, and educational goals. Medical schools' mission statement not only sets the standards to determine educational goals and outcomes but also provides an indicator to monitor and evaluate medical education quality.

Purpose: This study identified a methodology to provide optimal mission statements at medical schools through the framework of suggested decision-making method.

Methods: This study analyzed the focus of the mission development suggested by World Federation for Medical Education and Liaison Committee on Medical Education medical education standards and searched for appropriate decision-making methods based on these standards. In addition to validate the suggested framework of mission statement, case analysis of medical schools was conducted.

Results: Consequently, a mission development method that applies the mission statement based on stakeholders' priority (MSSP) was derived. The MSSP involves (1) content analysis, (2) candidate extraction, (3) priority evaluation, and (4) priority validation. The keywords of the mission system derived during this process were categorized and listed in ranks to be suggested as the mission, vision, and core values. The proposed MSSP was applied in two South Korean medical schools and, thereby, the mission, vision, and core values were determined for each medical school.

Conclusion: The two schools' case analysis verified MSSP's effectiveness as a decision-making methodology to gather and converge diverse opinions from stakeholders for the mission statement at the medical schools.

Key Words: Mission statement, Outcome-based medical education, Mission statement based on stakeholder priority, Medical schools

\section{Introduction}

\section{Outcome-based medical education, decision- making, and mission statement}

The traditional goal-oriented curriculum comprises setting learning objectives, selecting educational contents, teaching and learning the contents, and evaluating learners' academic achievement resulting from education. The learners' academic achievement depends on curricular management and the learners' competence. The traditional goal-oriented curriculum is a standardization model in the age of the Industrial Revolution that
Received: June 14, 2021 • Revised: August 2, 2021 • Accepted: August 19, 2021 Corresponding Author: Hyoseon Choi (https://orcid.org/0000-0003-0421-8042)

Chosun University College of Medicine, 309 Pilmun-daero, Dong-gu, Gwangju 61452, Korea Tel: +82.230.6419 Fax: +82.608.5314 email: goodluck@chosun.ac.kr
Korean J Med Educ 2021 Sep; 33(3): 215-226 https://doi.org/10.3946/kjme.2021.201 eISSN: $2005-7288$

(C) The Korean Society of Medical Education. All rights reserved. This is an open-access article distributed under the terms of the Creative Commons Attribution Non-Commercial License (http:// creativecommons.org/licenses/by-nc/3.0/), which permits unrestricted non-commercial use, distribution, and reproduction in any medium, provided the original work is properly cited. 
focuses on when and how students learn.

But there had been increasing calls in Western society for greater attention to be paid to the outcomes of education so that the return on investments in education could be evaluated during the 1980s and 1990s. These increasing calls for accountability were one reason for the rapid spread of various forms of outcomes-based education in countries such as the United States and the United Kingdom [1]. The outcomes-based education paradigm that shapes decision making and patterns of concrete action is the viewpoint that when and whether students learn successfully is more important than when and how they learn something [2].

In outcome-based learning, the decision-making in the entire educational process is centered on outcomeslearners' competence at the time of course completion, advancement, and graduation [3]. Hence, once the learners' outcomes are set, they are incorporated into the educational strategy, teaching and learning methods, and student evaluation procedures and methods [4]. In addition, the 'pre-set' graduate outcomes provide the context to consider the learning support system and environment for the completion of learners' learning and achievement of outcomes [5,6]. The outcome-based approach has reformed medical education by enabling criterion-reference evaluation, which is a powerful approach that can enhance the educational quality of learner-centered, individualized, and standard-oriented education [7].

The starting point of outcome-based education is the mission of the relevant medical education institution [3]. The mission reflects the educational philosophy whose realization is the medical school's aim, as well as suggesting the institution's purpose and goals and, thereby, serving as the standard for the intended learning outcomes. The mission sets the standards for decision-making in an organization, as well. The core values suggested by the mission determine priority and urgency in all areas, including the organization's constitution, budget, and human-power. The vision drives the determination and implementation of the educational responsibilities of the organization's members. The members, including the faculty, staff, and students of medical schools, recognize the educational vision through the mission system and strive to fulfil their responsibilities.

Therefore, the mission of a medical school is emphasized as the foundation of outcome-based education [8]. Accreditations by the World Federation for Medical Education (WFME) or Liaison Committee on Medical Education (LCME) consider the contents and procedures of "mission and outcomes" statements and the participation of members key standards [9-11]. Further, the institution's role in outcome-based education was highlighted by Spady [12] in 1993, who also emphasized the necessity of stating the mission that would guide all students to identify what must be done to enable successful learning and find appropriate methods to practice their learning.

However, a systematic methodology for mission statement at a medical school is yet to be proposed $[13,14]$. The methods of mission statement identified through published data are mostly expedient measures based on experience (a practical approach) or forms that impose the foundational ideology or values of the founder of the relevant medical institution or medical school. Such approaches not only do not conform to the LCME and WFME standards that highlight stakeholders' participation but also are inappropriate with respect to the learner-centered objectives of outcome-based education [9-11]. Many researchers call this current state 'a Garbage Can Model where everything is in unsystematic mixture' and highlight the need to develop systematized mission statement procedures and methodology [15-17]. 
This study identified a methodology to provide optimal mission statements at medical schools through the framework of suggested decision-making method.

\section{Decision-making models}

The decision-making process is comparable to the 'heart' in an administrative system, as it comprises the acts of goal accomplishment, value determination, and optimal alternative selection for an organization $[18,19]$. The most popular decision-making models with organizational applicability include the rational [20], satisficing [21], incremental [22], and mixed-scanning model [23].

The rational model is based on the theory that human beings make decisions according to their reasons and self-interest. The procedures are similar to and include the same steps as problem-solving: (1) goal setting, (2) data collection, (3) comprehensive data analysis, (4) suggestion of several alternatives, (5) evaluation of each alternative, and (6) selection of the optimum alternative. Contrarily, the satisficing model follows a realistic and empirical approach based on the fact that human beings cannot make completely rational decisions. Human beings know only a certain number of alternatives and can predict only certain parts of the consequences, which implies that they select an alternative that is satisficing, rather than optimum, within the limitations of their abilities.
The mixed-scanning model is a hybrid of the rational and incremental models and is also referred to as the third approach. In this model, the rational model sets the goal, and the incremental model determines the relevant details. The mixed-scanning model first scans a wide area and subsequently focuses on selected narrow areas that may pose problems.

\section{Methods}

This study proposes a systematic mission statement methodology that reflects both the social demands and stakeholders' opinions regarding a medical school. In the Table 1, first, in order to propose a methodology, global standards and decision-making models were reviewed to establish principles and procedures for mission development. Based on the review results, the framework of the mission establishment methodology was developed, and a case study was conducted by applying it to the actual establishment of the medical school mission.

\section{Review of global standards and decision- making models for principles and pro- cedures of mission statement methodology}

To this end, it analyzed the key points of the medical education standards for mission development suggested

\footnotetext{
Table 1. Research Procedure

\begin{tabular}{|c|c|c|}
\hline Method & & Model development \\
\hline $\begin{array}{l}\text { Review \#1: analysis of WFME and LCME global } \\
\text { standards }\end{array}$ & $\rightarrow$ & $\begin{array}{l}\text { Principles of mission development: (1) systemic consistency, (2) diverse } \\
\text { approaches, (3) optimal decision-making, and (4) circulation and continuation }\end{array}$ \\
\hline Review \#2: review of decision-making models & $\rightarrow$ & $\begin{array}{l}\text { Procedures of mission development based on combination of mix-scanning } \\
\text { model and optimal model: (1) content analysis, (2) candidate extraction, } \\
\text { (3) priority evaluation, and (4) priority validation }\end{array}$ \\
\hline $\begin{array}{l}\text { Suggestion of the mission development model } \\
\text { Application and validation of MSSP: case analysis }\end{array}$ & $\rightarrow$ & MSSP \\
\hline
\end{tabular}
}


by the WFME and LCME and reviewed the primary decision-making methodologies to select appropriate decision-making model and identify a procedure that conforms to the standards.

\section{Cases study on the validation of suggested framework}

The suggested framework of mission statement methodology was practically applied in two medical schools to conduct a case analysis, where the key elements of the mission were extracted to clarify its effectiveness and limitations. The Institutional Review Board of Wonkwang University approved this study (approval no., WKU UIRB 202004-017-01).

In case 1 , the case study conducted interviews, focus group interviews (FGIs), group discussions, and surveys. For the interview to collect resources and alternatives of mission, 10 faculties, three students, and four graduates were each interviewed. FGI was conducted with five students in each grade level, and 39 professors participated in the group discussion of mission statement. And in the survey for priority evaluation, nine alumni associations, 42 faculties, five administrative staff, and 15 students participated. In case 2, the case study conducted interviews, FGIs, and surveys. We interviewed the dean, seven staff members (faculties), three professors of the medical school, two staff at the university headquarters, and the head of health care at local government agencies to collect resources and alternatives of mission. And 12 students, two per grade, participated in the FGIs. To the survey for priority evaluation, 53 faculties, 451 students, 21 public officials from the department of health in local city hall, 40 graduates, and 50 alumni members responded.

\section{Results}

\section{Assumption of principles according to review of medical education accreditation standards}

The WFME and LCME accreditation standards emphasize two aspects of the mission statement [9-11]. First, the mission is a determinant of an institution's educational philosophy and direction for future development. Second, the mission and outcomes are set as the standards to determine the achievements of learners in terms of educational effectiveness.

1) Mission as a determinant of educational philosophy and future direction

The first standard emphasized by the WFME Global Standards for Quality Improvement of Basic Medical Education (2015, p. 16) is "mission and outcomes". Further, "Section 1.1 Mission" suggests the basic standards, as shown in Table 1 [9]. WFME accreditation standards emphasize a uniform liaison among the vision, educational strategy, and educational program, based on the mission [9]. The mission, in particular, should form a liaison with the outcomes, and each aspect of the standards requires an association between intended outcomes and the curriculum, student evaluation results, and so forth. For instance, "2. Educational program: 2.1 Framework of the program" suggests, "Overall curriculum in this document refers to the specification of the educational program, including a statement of the intended educational outcomes, the content/syllabus, the learning experiences and processes of the program" (2015, p. 20) [9].

Further, WFME accreditation standards emphasize the participation of stakeholders in stating the mission [9]. For instance, the basic standards in "1.4 Participation in 


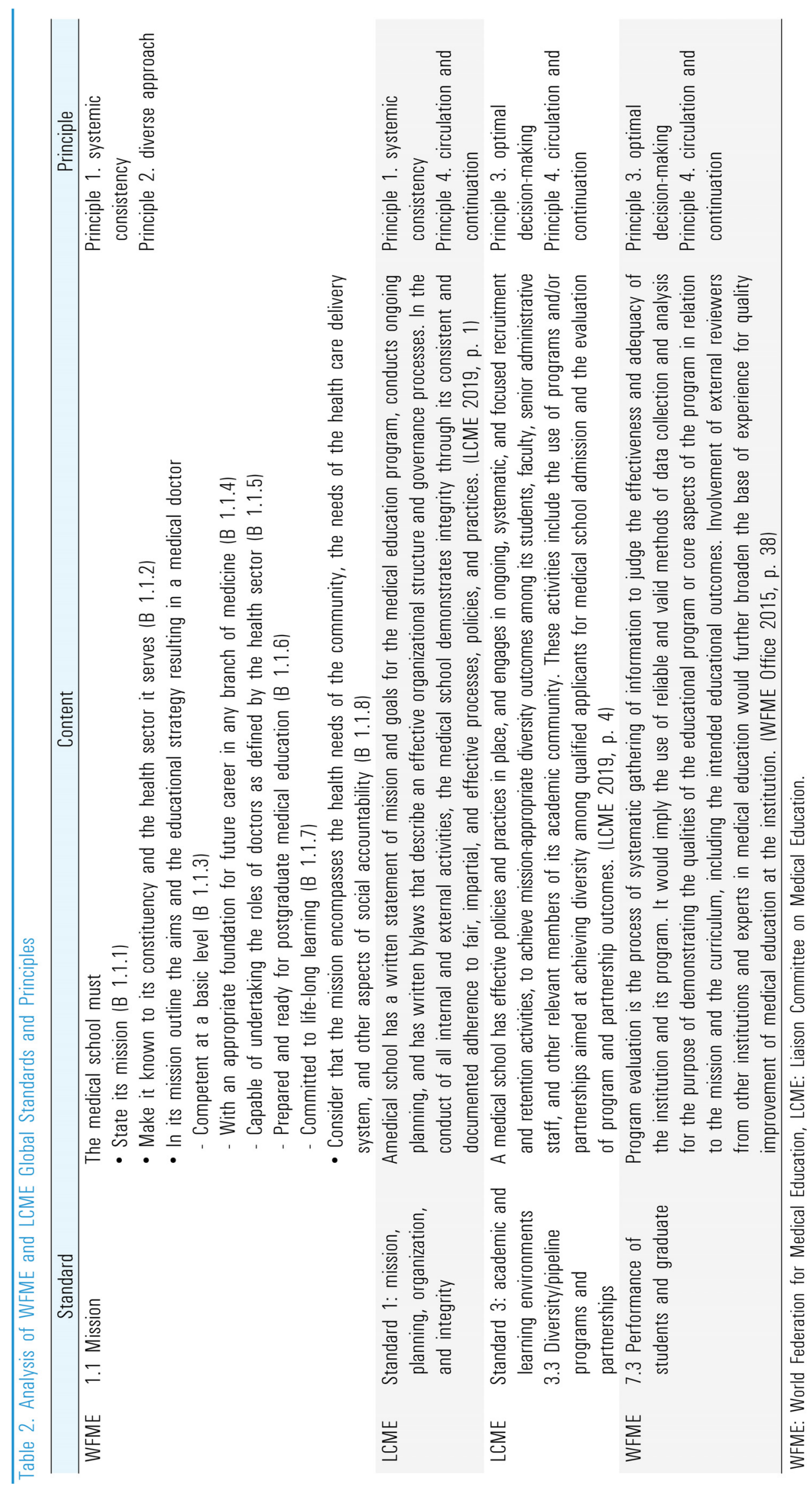


formulation of mission and outcomes" declares, "The medical school must ensure that its principal stakeholders participate in formulating the mission and intended educational outcomes (B 1.4.1)" (p. 19) [9]. Notably, the basic standards in "4.4 Student representation" declare, "The medical school must formulate and implement a policy on student representation and appropriate participation in mission statement (B 4.4.1)" (2015, p. 31) and, thereby, specifies the participation of students as stakeholders at medical schools [9].

Similarly, LCME accreditation standards emphasize the mission statement through "Standard 1: mission, planning, organization, and integrity" and declare that the planning, effective organization, and performance procedures should be based on the mission as shown in Table 1 [10]. In addition, each aspect of "Standard 3: academic and learning environments", including "3.3 Diversity/pipeline programs and partnerships", emphasizes that outcomes, policies, implementation, educational activities, and employment should be appropriate to the mission as shown in Table 2.

2) Mission as the standards to evaluate educational effectiveness

The WFME and LCME accreditation standards emphasize the close association between the stated mission and the intended outcomes, educational strategy, and curriculum $[9,11]$. Further, to measure educational effectiveness, both the WFME and LCME evaluate whether every component of education is functioning in accordance with the mission [9,11].

Among the WFME accreditation standards [9], the basic standards in "7. Educational Program: 7.3 Performance of students and graduates" declare, "The medical school must analyze the performance of cohorts of students and graduates in relation to mission and intended educational outcomes (B 7.3.1)” (2015, p. 39) and, thereby, promote evaluation by an external stakeholder or expert, in which the level of student performance is analyzed based on the mission and outcomes in Table 1 [10].

Currently, WFME accreditation standards are applied as the quality control activity framework in medical schools [11]. Similarly, LCME accreditation standards emphasize quality control activities in accordance with the mission, which is clarified by the expression "mission-appropriate" [10]. Specifically, this emphasis is apparent in "Standard 8: curricular management, evaluation, and enhancement", which mentions that educational goals should be mission-appropriate and program evaluation should conform to the school's goals.

3) Principles of mission statement according to medical education accreditation standards

The principles of the mission statement resulting from a review of medical education accreditation standards are as follows: (1) principle 1 (systemic consistency): the mission in liaison with outcomes, educational strategy, educational goals, and curricula; (2) principle 2 (diverse approaches): the participation of various stakeholders, including students; (3) principle 3 (optimal decisionmaking): the use of evaluated and analyzed priorities to make an optimal decision; and (4) principle 4 (circulation and continuation): the mission system based on continuous quality control and educational evaluation.

Table 2 summarizes the procedural phases and methods that represent the four principles.

\section{Mission development procedures applying mixed-scanning model}

Mixed-scanning model has a structured rational decision-making process and takes an algorithmic approach that emphasizes whether it meets the purpose of the institution [24]. A mixed-scanning model is appropriate for mission development because it is necessary to evaluate that the mission of the medical 
school meets the doctor's role and needs of society, and it is necessary to develop the mission according to a structured and rational procedure.

Therefore, we propose the mission development procedure of the mission statement based on stakeholders' priority (MSSP) by applying the decisionmaking process of the mixed-scanning model. Table 3 is a table comparing the decision-making process of the MSSP procedure and the mixed-scanning model. In MSSP, "negotiations", which is a key step in the mixed-scanning model, was further subdivided into content analysis, candidate extraction, priority evaluation, and priority validation.

\section{Suggested framework of the mission statement}

The mission development includes five phases: content analysis, candidate extraction, priority evaluation, priority validation, and feedback and improvement.

\section{1) Phase 1: content analysis}

The purpose of this phase is to derive educational goals using various methods. In this phase, methods such as literature analysis, case analysis, stakeholder interview, and workshop can be applied. For instance, a literature analysis may be conducted to address the changes in domestic and international healthcare systems and the trends of medical education imparted in medical schools. Furthermore, to clarify the goals of medical schools, a case analysis may be conducted after data collection from domestic and international medical schools and similar organizations, such as clinics or medical institutions. Here, the concepts that are commonly mentioned at each institution are derived. In addition, a method to gather the opinions of key stakeholders, such as students, physicians, the faculty, and the alumni, is applied. The methods of opinion collection involve brainstorming, FGI, and independent interview, depending on the purpose of the collection.

\section{2) Phase 2: candidate extraction}

The purpose of phase 2 is to extract the issues requiring focused review from among the broadly scanned opinions in the first phase. For this purpose, the candidates to be included in the mission system are extracted, and keywords are categorized for each area. The collected data are subjected to content analysis so that duplicated contents are distinguished from meanings requiring a sample analysis. Subsequently, the data are listed through open coding, and keywords are listed and categorized.

\section{3) Phase 3: priority evaluation}

Phase 3 provides a focused review of the issues selected in phase 2 . The priority analysis methodology requires the respondent to rank all items in the order of

Table 3. MSSP Procedure Comparing with Mixed Scanning Model

\begin{tabular}{ll}
\hline \multicolumn{1}{c}{ Mixed-scanning model } & \multicolumn{1}{c}{ MSSP } \\
\hline problem/opportunity identification & Sharing of the importance of mission development \\
Clarification of the decision evaluation criteria & Review of standards and criteria \\
Negotiations & Phase 1: content analysis \\
Identification of the decision alternative & Phase 2: candidate extraction \\
Alternatives evaluation based on criteria & Phase 3: priority evaluation \\
Making a decision: choosing an alternative & Phase 4: priority validation \\
Implementation of the decision & Mission statement \\
Assessment of the decision & Application of cases \\
\hline
\end{tabular}

MSSP: Mission statement based on stakeholders' priority. 
priority. The method enables a reliable estimation of the respondents' personal preferences and values.

Common priority questionnaires use a method that lists all the extracted candidates and allows the respondents to assign ranks to all items in the order of priority. However, this method requires the respondents to spend significant time and effort to rank all items. Alternatively, the Likert scale may independently be used for each item or the rank can be reduced to enable the selection of key items, for which ranks can be assigned.

Several methods are available to analyze priority according to the purpose of analysis. First, the frequency of the first rank item is computed to identify the item with the highest priority. Second, specific ranks are set, and the frequency is evaluated for the items within those ranks. Third, while selecting several high-priority items, appropriate weights are assigned to the selected ranks, which is followed by the summation of weights.

\section{4) Phase 4: priority validation}

Phase 4 aimed to check the mission's validity by examining its association with several factors, for instance, educational outcomes, purpose, strategies, and goals. In order to verify priorities, case analysis was conducted on the results of applying MSSP to two medical schools.

\section{Case analysis for MSSP validation}

At two medical schools in South Korea, the MSSP mission statement procedures proposed by this study were applied for mission statement in Table 4. The case study showed that the application of the overall process of the MSSP-based mission statement method was appropriate, and it was possible to supplement the specific technique for practical application at each phase.

\section{1) Case 1: A College of Medicine}

a. Background

Between April and October 2017, the mission statement procedures and methods proposed by this study were applied to design the mission.

b. Resource collection

The methods of data collection were other medical school case analysis, FGIs, and brainstorming by teaching faculties. The key stakeholders were categorized into several groups (faculty members, student representatives, and local community healthcare workers), and a semi-structured group interview focusing on issues such as the organization's current state, problems, strengths, and future visions was conducted. Among a group of four medical school participants (39 in total), a brainstorming session on the organization's visions and strategies for advancement was conducted.

c. Candidate extraction

Open coding was conducted on the collected data, and 293 keywords were derived: 56 from other medical school case analysis, 82 from the group interview, and 155 from brainstorming. Subsequently, duplicated contents or identical concepts were placed together, and the keywords were classified into three areas, education, research, and society, which led to the extraction of 25 candidates in each area and a total of 75 candidates.

\section{d. Priority evaluation}

Among the 25 candidates in each of the three areas, five candidates were extracted from medical school members (42 teaching staff, 15 student representatives, nine alumni representatives, and five faculty members), to whom priority was assigned using the rank reduction method. Subsequently, a questionnaire survey was conducted. Three methods were used to obtain the results of questionnaire responses: the (1) item with the highest frequency of first rank, (2) item with the highest 


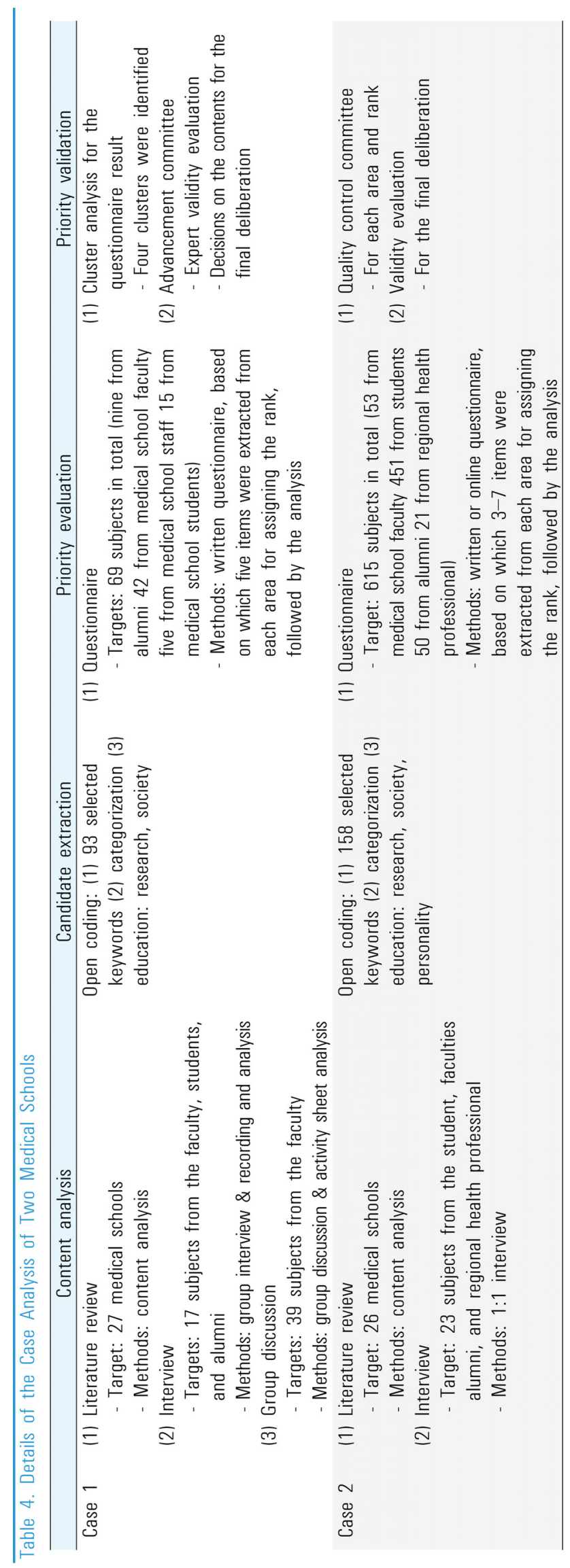

frequency of 1-5 ranks, and (3) item with the highest weight. For the three methods, the commonly mentioned items were selected.

\section{e. Priority validation}

The validity of each item was evaluated by the 12 members of the medical school advancement committee according to the highest score per area, which was calculated as previously described. Based on the majority vote, the candidates with the top three ranks were approved among the five in each area. The questionnaire results revealed that the opinions of various groups were considered based on cluster analysis. In addition, the associations with educational strategies, goals, and outcomes were mapped to report the validity.

\section{2) Case 2: B College of Medicine}

\section{a. Background}

The B College of Medicine applied the outcome-based curriculum in 2000, the mission was restated. In 2018, a task force was organized with 10 members of the quality control committee and, during the period from June 2018 to February 2019, the procedures and methods proposed in this study were applied for mission statement.

\section{b. Resource collection}

For the case analysis of domestic and international medical schools, data were collected from 26 schools (13 in South Korea and 13 in North America and Europe). The key stakeholders, such as medical school staff (8), student representatives (8), headquarters staff (2), professors representing the academic community (3), and local community healthcare representatives (1), were interviewed. The face-to-face interview was conducted in four areas: education, research, society, and personality.

c. Candidate extraction

Open coding was carried out on the collected data, and 101 keywords were derived: 57 from other medical school case analysis and 44 from individual interview 
and FGI. These keywords were classified into four areas: education (35 keywords), research (14), society (16), and personality (36). After putting together identical expressions or contents, 80 candidates (20 per area) were extracted.

d. Priority evaluation

In the questionnaire survey, 53 teaching staff, 451 students, 50 graduates, and 21 local community healthcare workers participated. Among the items in the aforementioned four areas, five were selected primarily and priorities assigned. For the questionnaire responses, weighting was performed based on their, and the final ranks were obtained by adding the values of each item.

e. Priority validation

The quality control committee stated the mission using the finalized keywords. In the process of formulation, the validity of the derived keywords was evaluated based on the contents by the quality control committee. Ultimately, the mission statement included the main keywords in each area.

\section{Discussion}

For medical schools providing outcome-based education, systematic mission statement and continuous improvement are prerequisites. This study proposed the mission statement procedures and methods that enable individual medical schools to promote stakeholders' participation through MSSP.

Most medical schools already have the mission statements as an educational need or accreditation requirement. However, the mission statement needs continual improvement to meet the needs of its stakeholders and social accountability. In this process, the four principles of MSSP-based mission development method can be considered as important: organic consistency, application of various approaches, optimal decision-making, rotation and continuity.

Although this study provides a useful methodology in medical school mission setting, some limitations were also identified in terms of scalability of the study. The main feasibility of the methodology was confirmed through the examples of two universities, but at the same time, the flexible use of the methodology was also found. The identical methods were applied in the two medical schools, the actual process of statement differed with respect to the (1) purpose of use, (2) implementing body, (3) application methods, and (4) results of decisionmaking. Although the flexible use of MSSP implies scalability that can be applied in many cases, it also has the potential to be problematic in its methodology robustness. This issue should be validated through further researches on more case application or minor revision if needed.

The MSSP-based mission statements development methodology has the advantage of rationally accepting the opinions of organizational members based on stakeholder priorities. Researchers have in mind the possibility that these approaches and stages of development methodology will be adopted not only as a mission development method but also as a major decision-making method in the educational system. If feasibility and scalability are confirmed through further research cases, MSSP can be widely used not only for mission setting but also as a decision-making and development methodology for medical education. In-depth research on MSSP in fields other than mission statement development is required.

\section{ORCID:}

Youngjon Kim: https://orcid.org/0000-0002-0445-526X; Hyoseon Choi: https://orcid.org/0000-0003-0421-8042 
Acknowledgements: None.

Funding: This work has supported by the National Research Foundation of Korea (NRF) grant funded by the Korea government (MSIT) (grant no., 2018R1C1B5085409).

Conflicts of interest: No potential conflict of interest relevant to this article was reported.

Author contributions: YJK: conception or design of the work, data collection, data analysis and interpretation, drafting the article, critical revision of the article, and final approval of the version to be published. HSC: conception or design of the work, data collection, data analysis and interpretation, drafting the article, critical revision of the article, and final approval of the version to be published.

\section{References}

1. Morcke AM, Dornan T, Eika B. Outcome (competency) based education: an exploration of its origins, theoretical basis, and empirical evidence. Adv Health Sci Educ Theory Pract. 2013;18(4):851-863.

2. Spady WG. Outcome-based education: critical issues and answers. Arlington, USA: American Association of School Administrators; 1994.

3. Harden RM. AMEE guide no. 14: outcome-based education: part 1-an introduction to outcome-based education. Med Teach. 1999;21(1):7-14.

4. McNeil HP, Hughes CS, Toohey SM, Dowton SB. An innovative outcomes-based medical education program built on adult learning principles. Med Teach. 2006; 28(6):527-534.

5. Lockyer J, Carraccio C, Chan MK, et al. Core principles of assessment in competency-based medical education. Med Teach. 2017;39(6):609-616.

6. Harden RM. Outcome-based education: the ostrich, the peacock and the beaver. Med Teach. 2007;29(7):
666-671.

7. Holmboe ES, Sherbino J, Englander R, Snell L, Frank JR; ICBME Collaborators. A call to action: the controversy of and rationale for competency-based medical education. Med Teach. 2017;39(6):574-581.

8. Shaikh AS, Prajapati P, Shah PD. Significance of the transition to outcome based education: explore the future. Paper presented at: National Conference on "Quest for Excellence in Teaching, Learning and Evaluation" (NAAC Sponsored); February 22-23, 2017; Anand, India.

9. World Federation for Medical Education. Basic Medical Education: WFME Global Standards for Quality Improvement: the 2015 revision. Ferney-Voltaire, France: WFME Office; 2015.

10. Liaison Committee on Medical Education. Functions and structure of a medical school: standards for accreditation of medical education programs leading to the MD degree. Washington DC, USA: Association of American Medical Colleges; 2019.

11. MacCarrick GR. A practical guide to using the World Federation for Medical Education (WFME) standards: WFME I: mission and objectives. Ir J Med Sci. 2010; 179(4):483-487.

12. Spady WG. Outcome-based education. Belconnen, Australia: Australian Curriculum Studies Association; 1993.

13. Olds GR, Barton KA. Building medical schools around social missions: the case of the University of California, Riverside. Health Syst Reform. 2015;1(3):200-206.

14. Batra S, Orban J, Guterbock TM, Butler LA, Mullan F. Social mission metrics: developing a survey to guide health professions schools. Acad Med. 2020;95(12): $1811-1816$.

15. Furman GC. School district approval for staff development: “Garbage Can” decision-making. Washington DC, USA: American Educational Research Association; 1986: 
16. Tamir E, Grabarski MK. Under pressure: why school managements use garbage can model of decision? Res Educ Adm Leadersh. 2018;3(1):1-28.

17. Kreiner K. Ideology and management in a garbage can situation. In: March JG, Olsen JP, eds Ambiguity and Choice in Organizations. Bergen, Norway: Universitetsforlaget; 1976:156-173.

18. Campbell RF, Gregg RT. Administrative behavior in education. New York, USA: Harper \& Bros; 1957.

19. Jones MH. Executive decision making: the Irwin series in management. Homewood, USA: Irwin; 1962.

20. Chaing C, McSweeney L. A behavioral model of rational choice. Competit Policy Int. 2010;6(1):241-258.

21. Brown R. Consideration of the origin of Herbert Simon's theory of 'satisficing' (1933-1947). Manag Decis. 2004; 42(10):1240-1256.

22. Lindblom CE. The science of "muddling through". Public Adm Rev. 1959;19(2):79-88.

23. Etzioni A. Mixed-scanning: a "third" approach to decisionmaking. Public Adm Rev. 1967;27(5):385-392.

24. Bakanauskienė I, Baronienė L. Theoretical background for the decision-making process modelling under controlled intervention conditions. Organ Vadyb Sist Tyrim. 2017;(78):7-19. 